\title{
Some lava flows may not have been as thick as they appear
}

\author{
Jonas Katona ${ }^{1,2}$, Xiaojing $\mathbf{F u}^{1,3}$, Tushar Mittal ${ }^{1,4}$, Michael Manga ${ }^{1}$, and \\ Stephen Self ${ }^{1}$. \\ ${ }^{1}$ University of California Berkeley, Berkeley, CA, United States \\ ${ }^{2}$ Yale University, New Haven, CT, United States \\ ${ }^{3}$ California Institute of Technology, Pasadena, CA, United States \\ ${ }^{4}$ Massachusetts Institute of Technology, Cambridge, MA, United States
}

\section{Key Points:}

- Lava lobes can heat and melt underlying lobes if erupted in close enough succession;

- Based on the time between successive eruptions, there are three regimes for lava lobe cooling: fused, in parallel, and in sequence;

- Macroscopic structures may not reflect the original lobe thicknesses.

Corresponding author: Jonas Katona, jonas.katona@yale.edu

Corresponding author: Xiaojing Fu, rubyfu@caltech.edu

Corresponding author: Tushar Mittal, tmittal2@mit.edu

This article has been accepted for publication and ${ }^{-1}$ undergone full peer review but has not been through the copyediting, typesetting, pagination and proofreading process, which may lead to differences between this version and the Version of Record. Please cite this article as doi: 10.1029/2021GL095202.

This article is protected by copyright. All rights reserved. 


\begin{abstract}
Individual lava flows in flood basalt provinces are composed of sheet pāhoehoe lobes and the 10-100 m thick lobes are thought to form by inflation. Quantifying the emplacement history of these lobes can help infer the magnitude and temporal dynamics of prehistoric eruptions. Here we use a phase-field model to describe solidification and remelting of sequentially emplaced lava lobes to explore additional processes that may lead to thick flows and lobes. We calibrate parameters using field measurements at Makaopuhi lava lake. We vary the lobe thicknesses and the time interval between eruptions to study the interplay between these factors and their impact on the thermal evolution of flows. Our analysis shows that if the time between emplacements is sufficiently short, remelting may merge sequentially emplaced lobes - making lava flows appear thicker than they actually were - which suggests that fused lobes could be another mechanism that creates apparently thick lava flows.
\end{abstract}

\title{
Plain Language Summary
}

The observation of thick basaltic lava flows has long been explained by vertical inflation. Here we explore an additional mechanism that could also create thick lava flows, where a sequence of thinner lobes that are emplaced on top of each other could fuse into one larger flow. Our analysis suggests the formation of thick lobes and flows by merging can occur if the lobes are emplaced relatively close to each other in time.

\section{Introduction}

Continental flood basalt (CFB) province eruptions contain the largest $\left(>1,000 \mathrm{~km}^{3}\right.$, Bryan and Ernst (2008); Self et al. (2014)) and longest ( 1000 km; Self et al. (2008)) lava flows. Since CFBs are frequently coeval with severe environmental perturbations including mass extinctions, ocean anoxic events, and hyperthermal events (Clapham \& Renne, 2019), understanding the physical process and time-scale of flow field emplacement would help quantify the release of volcanic gases that have environmental impacts (e.g., $\mathrm{CO}_{2}, \mathrm{SO}_{2}$ ). However, despite decades of work, the tempo and style of CFB eruptions remain poorly quantified.

CFB lava flow fields are composed of 5-100 m thick dominantly pāhoehoe lobes (Self et al., 1998, 2021). Given the general lack of large lava tubes in CFBs (Kale et al., 2020; Self et al., 1998), the primary process hypothesized for creating thick flows is the formation of pāhoehoe lobes by inflation (Hon et al., 1994). If the quasi-continuous magma flux into individual lava lobes is sufficient, the solidifying surface crust can continuously rise due to increasing pressure (Hoblitt et al., 2012; Hon et al., 1994). If the lateral magma pressure is large enough, the lobe can propagate laterally by sporadic breakouts (Hamilton et al., 2020; Hon et al., 1994; Kauahikaua et al., 1998). This process has been observed in modern meter-scale Icelandic and Hawaiian lobes (Self et al., 1998). In addition, the lobe structures in CFB flows have similar internal characteristics as Hawaiian inflated lobes (Vye-Brown et al., 2013). The maximal final inflated lobe thickness in Hawaiian flows, however, is only 10-15 m (Kauahikaua et al., 1998), which is smaller than many CFB flows (up to 80-100 m; Puffer et al. (2018); Self et al. (2021)). This suggests that, for typical basaltic magmas, the yield strength of the crust is insufficient to support the large lateral pressure gradients that would arise from much thicker flow lobes. Furthermore, lava flow inflation has been shown to potentially require pulsating eruptive conditions that may not always be possible (Rader et al., 2017). Thus, a fundamental question remains: How do CFB flows become so thick? This question underlies a broader question: What are the eruptive conditions and fluxes associated with common $\sim 1000 \mathrm{~km}^{3}$ scale CFB flows? 
In this study, we quantitatively analyze a physical process that can, in addition to flow inflation, also lead to apparently thick lobes and flows: The final flow is an amalgamation of smaller lobes, piled on top of each other quickly enough to remelt the intervening solidified crust (Basu et al., 2012, 2013). We study this process for a wide range of flow thicknesses. While our model could still be applicable to shallow flows undergoing predominantly unidirectional solidification and moving at low velocities, the model simulated in this paper cannot capture the inherently $3 \mathrm{D}$, meandering nature of phoehoe flows, especially those present during the amalgamation of small $(<1 \mathrm{~m})$, predominantly non-inflated phoehoe lobes, e.g., in lava piles where hummocky phoehoe or compound lavas are forming (e.g., Baloga et al., 2001; Hamilton et al., 2020). Thus, we focus most of our discussion on large CFB flow lobes where our model is best suited, since for such flows, the dynamics in the non-vertical directions are dominated by those in the vertical (Hon et al., 1994; Wright \& Okamura, 1977).

We use simplified magma solidification models to constrain how quickly two subsequent flow lobes must be emplaced to fully merge, thereby providing constraints on CFB eruption tempo. In section 2, we describe a new phase-field model for lava lobe cooling, and then simulate the solidification of a single flow lobe and two sequentially emplaced flow lobes using our model in 1D. In section 3, we use these results to outline three distinct regimes (fused, in parallel, in sequence) for inter-lobe cooling. Finally, in section 4, we compare our results with observations to assess whether remelting can help explain thick CFB flows and analogous thick flows in other planetary settings. Our results are used to put lower bounds on how quickly CFB flow fields were emplaced in order to preserve multiple lobes within a single flow.

\section{A phase-field model of lava solidification}

\subsection{Model equations}

The phase-field framework is a mathematical approach to describe systems out of thermodynamic equilibrium (Anderson et al., 1998), first introduced in the context of solidification processes and phase transitions of pure or multi-component materials (Boettinger et al., 2002; Cahn \& Hilliard, 1958). The framework evolves the solidification front via a system of partial differential equations, avoiding the need for explicit tracking of the moving interface as traditionally done in the Stefan problem (Anderson et al., 1998). Here, we consider a simplified model of lava solidification where we track the binary solidification of lava through a phase variable, denoted $\phi(\phi=1$ for the melt and $\phi=0$ for the solid phase), with corresponding temperature, $T$. The evolution of $\phi$ and $T$ can be described by the following system of partial differential equations:

$$
\begin{array}{r}
\tau \frac{\partial \phi}{\partial t}+\nabla \cdot\left(-\omega_{\phi}^{2} \nabla \phi\right)=-\frac{d \Gamma}{d \phi}-\frac{L}{H} \frac{\left(T-T_{m}\right)}{T_{m}} \frac{d \Psi}{d \phi} \\
\frac{\partial T}{\partial t}+\nabla \cdot(-\alpha \nabla T)=\frac{L}{c_{p}} \frac{d \Psi}{d \phi} \frac{\partial \phi}{\partial t}
\end{array}
$$

where $T_{m}$ is the melting temperature of the lava, $\alpha$ is the thermal diffusivity, $\omega_{\phi}$ is the interfacial width coefficient, $\tau$ is the characteristic time of solidification (not the solidification time of a lobe), $L$ is the latent heat of fusion for lava, and $H$ is the energy barrier; see Table S1 for the values of these parameters used in this work, which are adopted from the typical thermal properties of basaltic melt (Audunsson \& Levi, 1988; Cooper \& Kohlstedt, 1982; Patrick et al., 2004; Peck et al., 1977; Worster et al., 1993; Wright \& Marsh, 2016). $\nabla$ is a partial differential operator defined in text $\mathrm{S} 2 . \Gamma=\Gamma(\phi)$ and $\Psi=\Psi(\phi)$ are auxiliary functions of the phase-field model (see text S1). Because we are working with a binary phase-field model, we do not model the so-called "mush zone" that exists in actual lavas (e.g., Wright \& Marsh, 2016). Consequently, we combine the solidus and liquidus temperatures as $T_{m}=1070^{\circ} \mathrm{C}$, which is within the range of rea- 
sonable values reported in literature for the liquidus of typical basaltic magmas (e.g., Cashman \& Marsh, 1988; Wright \& Marsh, 2016).

We impose convective and radiative boundary conditions at the surface while fixing the temperature at the bottom of the domain. Moreover, we integrate our phase-field equations over a sufficiently large domain such that the lower boundary does not influence the temperature and phase during solidification (see text S2). Because the horizontal dimensions (kilometers) are much larger than the vertical scale (meters) for the flows of interest here, we perform our simulations in a 1D vertical dimension. Consequently, the conductive heat transfer will be primarily in the vertical direction. We provide additional details regarding the numerical scheme we used in text S3.

\subsection{Model validation and limitations}

The phase-field modeling parameters $\tau$ and $\omega_{\phi}$ are derived in terms of measurable quantities in text S1 using the approach in Kim and Kim (2005), and then calibrated based on field data collected from Makaopuhi lava lake (Wright \& Marsh, 2016; Wright \& Okamura, 1977; Wright et al., 1976). The calibration results show that the model agrees with the lava lake data for a range of parameters (see Figure S1 and Table S1); we ultimately choose $\omega_{\phi}=3.22 \times 10^{-1} \mathrm{~m}$ and $\tau=2.90 \times 10^{6} \mathrm{~s}$ in our simulations, both of which are well within these ranges.

As an additional test, we use the calibrated parameters from Makaopuhi lava lake to simulate measurements of inflating phoehoe lava flows on the Klauea volcano in Hawaii, taken from Hon et al. (1994). The results (Figures S2-S3) show decent agreement at depths deeper than $\sim 10 \mathrm{~cm}$ below the cooling surface, although there is noticeable disagreement near the surface. These validation efforts demonstrate that, while our model robustly captures macroscopic cooling of lava across multiple data sets, it lacks accuracy in describing the temperature evolution in the uppermost section of cooling lava $(\sim 10 \mathrm{~cm})$. One explanation is that the bubbles and vesicles that accumulate near the lava's surface (Audunsson \& Levi, 1988; Cashman \& Kauahikaua, 1997; Self et al., 1998) tend to decrease $\alpha$ near the surface (Keszthelyi, 1994). We also neglect the temperature dependence of $\alpha$ (Jaupart \& Mareschal, 2010). While it is possible to include these effects in the model, it would also introduce additional parameters that are challenging to calibrate, and would also require resolving multiphase physics and chemistry at the sub-centimeter spatial scale and sub-second time scale. The fact that we neglected to include such effects adds an increasingly non-negligible degree of uncertainty to our results as the lobe size decreases, the degree of which should be explored in future studies.

Nevertheless, the model presented here, although simplified, still captures the firstorder effects of latent heat and thermal diffusion that dominate lava cooling while allowing us to simulate cooling processes spanning from seconds to years. From our validation tests above, we see that any surface effects appear to be negligible for depths below $\sim 10 \mathrm{~cm}$. This is especially true for larger lava lobes, where the influences of latent heat release and diffusion on the velocity of the solidification front and evolution of temperature profiles are especially greater in both spatial and temporal extent than those which are due to the surface and near-crust phenomena aforementioned (Patrick et al., 2004; Wright \& Marsh, 2016; Wright \& Okamura, 1977; Wright et al., 1976).

\subsection{Setup for lava cooling simulations}

We use the model to perform two types of simulations. We first simulate solidification of a single lava lobe of thickness $h$ to obtain the total time $t_{h}$ it takes to reach complete solidification for a single lobe of thickness $h$. The results are used to design the second set of simulations, where we simulate sequential emplacement of two lava lobes of equal thickness $h$, separated by a time period of $t_{\mathrm{emp}}$. We consider 17 different lobe thick- 
ness $h$, from $0.1 \mathrm{~m}$ to $20 \mathrm{~m}$, to explore the behaviors of both thin pāhoehoe lobes $(<1$ $\mathrm{m}$ ), as seen in recent Klauea eruptions (Lundgren et al., 2019; USGS, 2019), and thick lobes $(\gg 1 \mathrm{~m}$ ), as seen in Columbia River Basalt Group and other CFBs (Self et al., 2021). For the sequential emplacement simulations, we scale $t_{\mathrm{emp}}$ relative to $t_{h}$ and explore nine different emplacement intervals for each thickness: $t_{\mathrm{emp}}=2^{-4} t_{h}, 2^{-3} t_{h}, \ldots, 2^{4} t_{h}$. Here, $t_{\mathrm{emp}}$ is sampled along multiple orders of magnitude in order to capture a wide range of cooling times. The lower bound for the emplacement intervals is based on typical phoehoetype flows (Anderson et al., 1999; Hon et al., 1994) while the upper bound is provided by examples from flood basalt provinces (Self et al., 1996; Thordarson \& Self, 1998).

\section{Results}

We perform a total of 153 simulations of the sequential emplacement of two lava lobes and identify three distinct qualitative regimes of inter-lobe solidification. These regimes can be delineated based on the ratio between $t_{\mathrm{emp}}$ and the conductive time scale, the latter of which is more precisely described by $t_{h}$, but approximated here by $h^{2} / \alpha$ to be more physically interpretable (see Figure S4 for how well the approximation $t_{h} \sim h^{2} / \alpha$ holds). Below, we describe each regime in detail with examples in Figure 1 for the case of $h=$ $10 \mathrm{~m}$ lava lobes.

In sequence $\left(t_{\text {emp }}>0.06 h^{2} / \alpha\right)$ : The first lava lobe completely solidifies before the second lobe is emplaced (Figure 1, left). The cooling times of both lobes are similar and the bottom lobes does not remelt.

In parallel $\left(0.01 h^{2} / \alpha<t_{\mathbf{e m p}}<0.06 h^{2} / \alpha\right)$ : As indicated by the narrowing of both black contours in the top plot and the decreasing melt thickness in the lower plot with time, both lava lobes solidify for overlapping time, but the interface between them does not remelt (Figure 1, middle). Because the bottom lobe is hot, the collective cooling of both lobes is slower than for in sequence flows, as indicated by the decrease in slope in Figure 1 (bottom middle).

Fused flow $\left(0<t_{\mathrm{emp}}<0.01 h^{2} / \alpha\right)$ : After emplacement, the solidified portion of the lower lava lobe remelts completely, after which both lobes combine to form a single, larger lobe. For early times, there are four solid-melt interfaces that correspond to the simultaneous solidification of two independent lobes. However, the two interior interfaces eventually disappear, which marks the merging of the two lobes. The remelting event is also evident when we track the total melt thickness over time (Figure 1, right). After the arrival of the second lobe (indicated by the red dot), the total melt thickness increases slightly at some point, corresponding to the remelting that caused a reduction in the solid fraction. Despite a monotonic loss of entropy over time after the second flow arrives, remelting can still occur, since some sensible heat is converted into latent heat. In the other two regimes, the melt thickness never increases after the arrival of the second lobe.

We compile the results from all the simulations into a regime diagram in Figure 2 , which shows the combined control of individual lobe thickness and emplacement intervals on the inter-lobe solidification during sequential emplacement. We map the three regions of inter-lobe solidification, separated by two boundaries extrapolated from our results: $t_{\mathrm{emp}}=0.01 h^{2} / \alpha$ and $t_{\mathrm{emp}}=0.06 h^{2} / \alpha$. These regimes and the boundaries that define them are universal for both thin and thick lobes.

The bottom four panels in Figure 2 also illustrate examples of lava flows that appear to have been emplaced in parallel or in sequence, as suggested by their distinct interlobe boundaries. These examples are also marked in the regime diagrams, where the vertical position of the marker corresponds to the minimum emplacement interval predicted by our model (e.g., $t_{\mathrm{emp}}=0.01 h^{2} / \alpha$ ). The hexagonal marker corresponds to $\sim 10 \mathrm{~cm}$ thin lobes seen in the Kupaianaha flow field (Self et al., 1998) that are predicted to have 
been emplaced at least $\sim 4$ minutes apart. The square marker corresponds to $\sim 0.5 \mathrm{~m}$ thin lobes seen in Elephanta Caves (Deccan Traps) (Patel et al., 2020), and are predicted to have been emplaced at least $\sim 2$ hours apart. The circular marker corresponds to $\sim 8 \mathrm{~m}$ thick lobes - part of a single flow and seen in Rajahmundry Traps (Fendley et al., 2020a) - that are predicted to have been emplaced at least $\sim 20$ days apart. The star-shaped marker corresponds to $\sim 20 \mathrm{~m}$ thick lobes seen in Columbia River Basalts (Self et al., 2021) that are predicted to have been emplaced at least $\sim 4$ months apart.

\section{Discussion}

There is a body of literature that commonly assumes that even the thickest $(>40$ m) CFB flows were formed by flow inflation (e.g., Anderson et al., 1999; Rader et al., 2017; Self et al., 1996, 1998), inspired by observations of Hawaiian lava flows (Hon et al., 1994). However, our analysis suggests that even thick (30-40 m total height) flows could have arisen by fusing lobes together if eruption intervals are shorter than a month or two. One practical challenge in testing our proposed mechanism is the ability to identify fused flow boundaries in the field, since fusing would remove structures corresponding to the crusts of the two lobes. However, some relics of the originally distinct flows may remain, such as compositional differences (Reidel, 2005; Vye-Brown et al., 2013) and possibly structures indicative of fused flow crusts, such as multiple differential cooling zones and vesiclerich horizons (see text S6 and Figure 3). Moreover, vesicle-rich horizons are commonly interpreted as remnants of inflation (Self et al., 1998; Thordarson \& Self, 1998), and so the presence of these alone may not be sufficient to distinguish between lobe inflation and fusion, or at least with our current understanding of how the observable characteristics of said horizons reflect their formation.

\subsection{Potential example of a fused CFB flow}

One potential example of a fused CFB flow is the $\sim 70 \mathrm{~m}$ thick Cohassett Flow from the Columbia River Flood Basalts. The flow is part of the Grande Ronde Basalt Group and is a member of the Sentinel Bluffs Member lava flows in Pascoe Basin (e.g., McMillan et al., 1989; Reidel, 2005, see Figure 3A for a map of outcrops and drill core data). As shown by the annotated picture in Figure 3B, the Cohassett has a multi-tiered structure with alternating entablatures and colonnades (see text S6 for a description), as well as a $6.5 \mathrm{~m}$ thick internal vesicular zone (IVZ; $\sim 20 \mathrm{~m}$ from the flow top, Figure 3B,C,D) with many $\sim 1 \mathrm{~cm}$ diameter vesicles (McMillan et al., 1989; Tomkeieff, 1940). To first order, the Cohassett flow in the outcrops (Figure 3) appears to be a single thick sheet lobe. The Cohassett flow also exhibits one of the most striking geochemical variations amongst the Grande Ronde flows. The flow has an approximate vertical bilateral symmetry geochemically centered just under the IVZ, as seen from data across sections more than $50 \mathrm{~km}$ apart (Figure 3). Using characteristic patterns in $\mathrm{TiO}_{2}, \mathrm{P}_{2} \mathrm{O}_{5}$ (and other major and trace elements), Reidel (2005) defined four distinct compositional types within the flow: California Creek, Airway Heights, Stember Creek, and Spokane Falls. Typically, these compositional types are separated by a vesicular horizon. For example, a horizon $\sim 13-15 \mathrm{~m}$ from flow top separates massive basalt of the California Creek composition from the Airway Heights composition. Similarly, the Airway Heights and Stember Creek transition is characterized physically by a series of large vugs. The IVZ acts as the contact between the Spokane Falls and the Stember Creek compositional types (Figure 3B,C,D). Finally, a vesicular horizon $\sim 40 \mathrm{~m}$ from flow top defines the transition from the Spokane Falls back to the Stember Creek compositional types. Interestingly, the subsequent compositional type changes from Stember Creek to California Creek/Airway Heights lack clear vesicular horizons (Figure 3).

Corresponding spatially with these geochemical changes, the Cohassett flow also exhibits systematic changes in plagioclase abundance and fine-grained fraction (groundmass, 
Figure 3C based on data from Reidel, 2006). In particular, the flow part comprising the IVZ and the Spokane Falls composition member has a fine fraction significantly more indicative of a flow top rather than the flow interior. Thus, this flow interior was potentially emplaced rapidly and cooled faster than a continuously inflating flow lobe interior (McMillan et al., 1989; Philpotts \& Philpotts, 2005). The IVZ-entablature-colonnade sequence in the Spokane Falls lava further supports the conclusion that the cooling rates in this part of the flow were more akin to a flow top (DeGraff et al., 1989; Forbes et al., 2014). Even on an overall flow scale, the textural data for the Cohassett flow are inconsistent with the slow cooling expected for a $\sim 70 \mathrm{~m}$ flow; the plagioclase crystal size does not significantly change throughout the flow, unlike the case for a slowly cooling ponded lava lake (Cashman \& Marsh, 1988; Philpotts \& Philpotts, 2005).

Previously, Reidel (2005) proposed that the Cohassett flow formed via the combination of different sheet flows (for each compositional type), each sourced from a different magma reservoir and eruptive vent. These individual flows sequentially intruded into the Cohassett flow as flow lobes and inflated it to its final height. However, the Reidel (2005) model does not explain the abrupt shift to distinct compositional types along with sharp vesicle horizons (Figure 3B, B1-B2) without any signs of magma mixing or shear instabilities, despite intrusion and transport within the Cohassett flow for $10 \mathrm{~s}$ of $\mathrm{km}$. Alternatively, Thor Thordarson (personal communication; see also Vye-Brown et al. (2013)) proposed that the Cohassett flow was formed by semi-continuous inflation with changing magma compositions in the magmatic system feeding the eruption. As evidenced by observations from some modern long-lived basaltic eruptions, e.g., $\mathrm{Pu} u \overline{\mathrm{O}} \overline{\mathrm{o}}$ eruption at Klauea, Hawai'i from 1983 to 2018 (Garcia et al., 2021), these changes can be relatively abrupt and could correspond with the presence of a vesicle horizon. Philpotts and Philpotts (2005) proposed that crystal-mush compaction in an inflated sheet lobe can also partially explain the observed geochemical variation and bubble segregation.

Here, we put forward a third alternative, building upon the original idea proposed by Reidel (2005): We posit that the Cohassett flow is an example of a fused flow with multiple flow lobes. Suppose the Cohassett was close to the boundary between the fused and in-parallel flow types (Figure 2). In that case, the presence of separating vesicle horizons as well as high fine-grained size fraction, especially for the Spokane Falls type, can be explained. Within this scenario, each constituent $\sim 10-20 \mathrm{~m}$ lobe would have to be emplaced within a few months of the previous lobe. However, more detailed modeling work specifically focused on the Cohassett as well as textural analysis, e.g., stratigraphic crystal size distributions to estimate cooling rates (Cashman \& Marsh, 1988; Giuliani et al., 2020), would be needed to ascertain which of the proposed models is correct and if Cohassett is indeed a fused flow.

It is similarly challenging to distinguish between in parallel and in sequence flows based on field volcanological observations alone without detailed textural analysis. One potential distinguishing feature may be the $2 \mathrm{D}$ shape of the bottom flow lobe in a in parallel flow since it will be visco-elastically deformed by the load from the overlying flow lobe (Abbott \& Richards, 2020). One consequence of this would be the formation of squeezeup structures at flow lobe edges seen in some CFB flow edges, e.g., for the Western Ghats and the Rajahmundry Trap flows in the Deccan CFB (Dole et al., 2020; Fendley et al., 2020b).

\subsection{Relevance of fused flows for planetary geology}

Our results also have implications for inferring eruption conditions on other planetary bodies (Venus, Mars, Mercury, the Moon) where we can only observe the final lava flow thickness from remote sensing observations. Below, we briefly summarize observations of thick lava flows on each of these bodies: 
- Venus: With a surface area $\left(\sim 60,000 \mathrm{~km}^{2}\right)$ comparable to many CFB flows (Moore et al., 1992; Wroblewski et al., 2019), the most striking example of a thick lava flow $(\sim 100-200 \mathrm{~m})$ on Venus is the Ovda Flactus flow. Although initially classified as a potentially high silica or rhyolitic flow, morphological analysis by Wroblewski et al. (2019) shows that Ovda Flactus has an emplacement rheology most consistent with basalt. Several other basaltic flows mapped across Venus have thicknesses ranging between 30-100 m (Guest et al., 1992; Lancaster et al., 1995; MacLellan et al., 2021; Moore et al., 1992; Zimbelman, 2003). We envision that our proposed process of fused flows can help explain these large flow thicknesses, especially since cooling rate during solidification on Venus will be smaller ( $\sim 30-40 \%$ compared to Earth) due to higher surface temperatures (Snyder, 2002). Correspondingly, individual flow lobes can be separated by longer times and still fuse together.

- Mars: There is a wide range of estimated flow thickness for Martian lava flows with values ranging from a few meters to $\sim 100-125 \mathrm{~m}$ (Hiesinger et al., 2007; MouginisMark \& Rowland, 2008; Mouginis-Mark \& Yoshioka, 1998; Peters, 2020; Zimbelman, 1998). In particular, both the Tharsis volcanic province and the Elysium Planitia region on Mars have a number of flows with typical thickness greater than 40 $\mathrm{m}$ (Peters, 2020). These flow thicknesses are challenging to explain with inflation, but may be explained by lobe fusion. Since the mean Martian surface temperature $\left(-60{ }^{\circ} \mathrm{C}\right)$ is colder than Earth's, the lava solidification time is about $5 \%$ shorter than on Earth (based on results from a model with Martian surface temperature). Since Martian surface gravity is $\sim 38 \%$ of Earth's, flow lobes may inflate to greater thickness before overcoming basalt yield strength to form new breakouts.

- Mercury: J. Du et al. (2020) used observations of partially and completely buried impact craters on Mercury to estimate lava flow thicknesses and found values between 23-536 m with a median of $228 \mathrm{~m}$ (with potentially even thicker flows), consistent with some other estimates, e.g., $180 \mathrm{~m}$ (Wilson \& Head, 2008). Even if we account for the difference in surface gravity ( $38 \%$ of Earth's), the median thickness of $228 \mathrm{~m}$ translates to $86 \mathrm{~m}$ of Earth's equivalent (in terms of flow dynamics; the cooling times are independent of gravity).

- Moon: Lunar mare basalts have a range of flow thicknesses, from thin $(<1 \mathrm{~m})$ to thick $(>100 \mathrm{~m})$. These estimates come from a combination of in situ observations by Apollo Astronauts, remote sensing, and lunar penetrating radar on rovers (Chen et al., 2018; Gifford \& El-Baz, 1981; Hiesinger et al., 2011; Rumpf et al., 2020; Spudis \& Guest, 1988). Since lunar gravity is only about $16 \%$ of the terrestrial gravity, lobe inflation could form much thicker flows (a $15 \mathrm{~m}$ flow lobe on Earth will be equivalent to a $91 \mathrm{~m}$ lobe on Moon with respect to lateral pressure gradients). Thus, except for the thickest flows (>100 m), flow fusion may not be required to explain the observed lunar flow thicknesses.

In aggregate, there are a number of very thick planetary basaltic flows. We posit that these could be potentially emplaced by the same process as we are proposing for thick terrestrial CFB flows (fused flow lobes). However, more data and careful analysis is necessary to rule out the possibility that these were primarily formed via flow lobe inflation.

\subsection{Implications for eruption rates}

In combination with viscous flow models for channelized lava flows (e.g., Jeffrey's equation), measurements of lava flow thickness have been used to estimate the mean flow velocity and viscosity (e.g., Baloga et al., 2001, 2003; Chevrel et al., 2018; Glaze et al., 2003; Harris \& Rowland, 2001). Frequently, estimated flow velocities are used in combination with constraints on total flow volume to calculate an eruption duration. However, these calculations are predicated on the assumption that the final flow thickness is representative of the molten channelized flow thickness at the time of eruption. Since the velocity depends strongly on the lava flow thickness (velocity $\sim$ thickness $^{2}$ for a New- 
tonian fluid), an incorrect estimate could strongly impact the estimates of eruption rate $(\sim$ flow rate $\times$ thickness) (Baloga et al., 2003). Suppose that the observed lava flow results from the merging of two (or more) equally thick flow lobes. Then, the models will overestimate instantaneous effusion rates by about a factor of $2^{3}=8$ (or larger for three or more fused lobes) if the final flow thickness is used as the characteristic open channel lava flow thickness, i.e., with an error that grows $\sim$ cubically. This issue is further exacerbated by how, during the emplacement of phoehoe flows by inflation, the "active" molten part of the flow is smaller than the thickness of each lobe.

In the other end-member, wherein the total observed flow thickness is assumed to be only a consequence of lava flow inflation, most models require a relatively continuous, long-lived effusion rate that gradually thickens the flow lobe (Hamilton et al., 2020; Hon et al., 1994; Kauahikaua et al., 1998; Self et al., 1998). However, if the CFB flow is a fused flow, each constituent flow lobe must inflate to a smaller thickness. Consequently, since the two lobes can be sequentially emplaced days to months apart, the total eruptive duration can be smaller and/or allow for more effusion rate variations but will still form a single fused flow in the end. In conclusion, the possibility that different flow lobes merged into a single flow has important implications for inferences of effusion rate, especially its steadiness.

\section{Conclusion}

We provide a theoretical lower bound on emplacement interval that distinguishes a fused flow from non-merged flows. For instance, a distinct boundary between two lobes of $10 \mathrm{~cm}$ each suggests that they were emplaced at least 4 minutes apart $\left(t_{\mathrm{emp}}>0.01 h^{2} / \alpha \approx\right.$ 4 minutes). The same calculation for two $20 \mathrm{~m}$ thick lobes suggests that the emplacement interval is at least 4 months if a distinct boundary exists between the two lobes. Furthermore, while it is often assumed that the $10-100 \mathrm{~m}$ thick lobes found in flood basalt provinces are primarily formed from inflation, our results suggest that these large lobes also could have been formed by smaller lobes emplaced in quick succession. Relatedly, some volcanological studies could be overestimating eruption rates and flow velocities by assuming that solidified flows belong to one flow rather than a series of smaller flows that merged with little to no trace of their original separation. While more work is necessary (especially empirically) to distinguish conclusively between a large, solidified flow that formed primarily via multiple-lobe emplacement vs. the usually assumed mechanism of inflation, we still propose that the emplacement and subsequent fusion of multiple lobes is a plausible, additional process for forming CFB flows.

Noting some limitations, we also demonstrate the effectiveness of using phase-field models in simulating observed lava solidification over a range of timescales faithfully (Hon et al., 1994; Wright \& Marsh, 2016; Wright \& Okamura, 1977; Wright et al., 1976), with some local deviation $\sim 10 \mathrm{~cm}$ near the top surface. The phase-field model can be generalized to arbitrary domains in higher dimensions and account for additional complexities in thermal diffusivity, flow, and nonlinear rheology. 


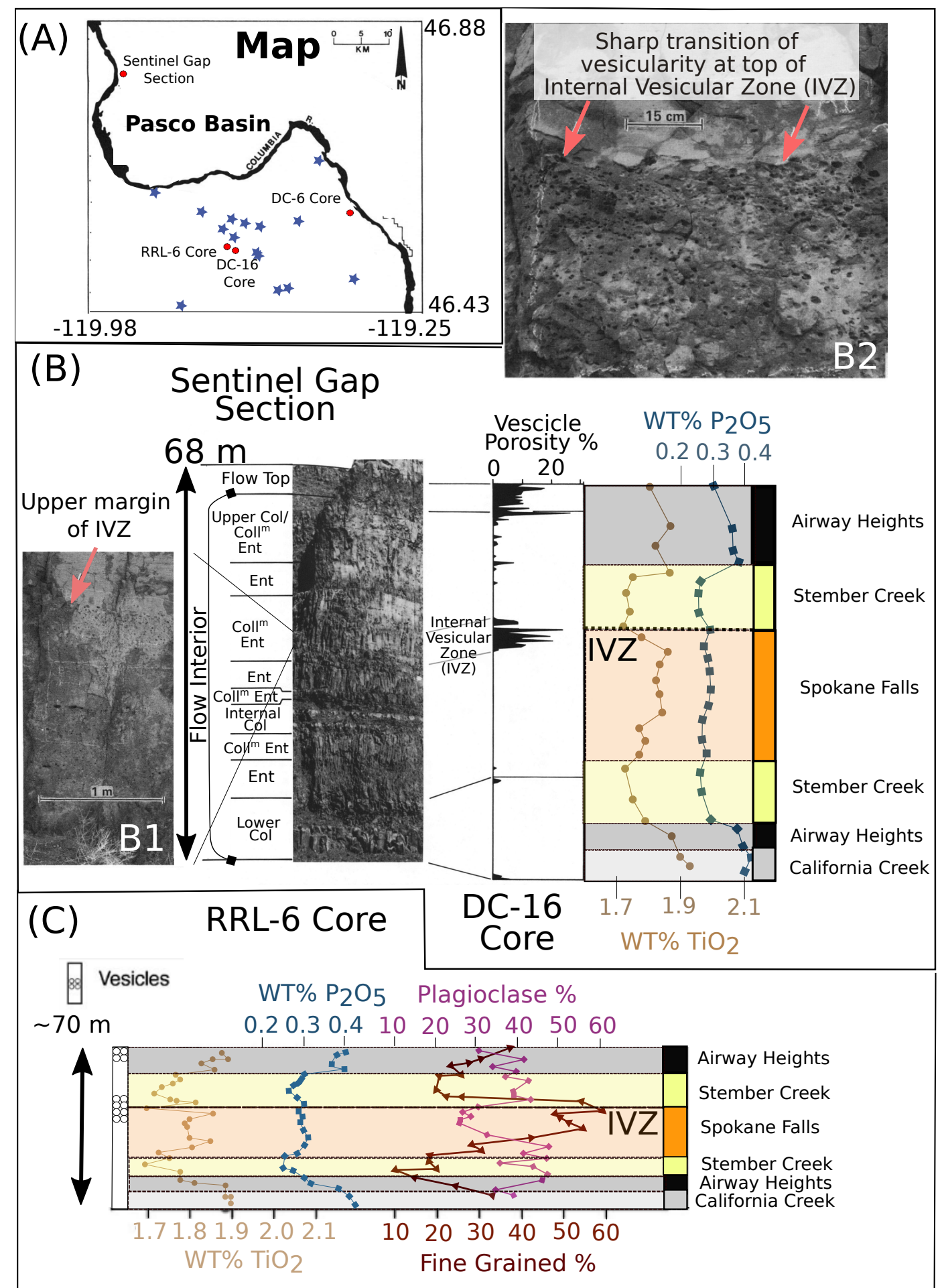

\section{(D) DC-6 Core}

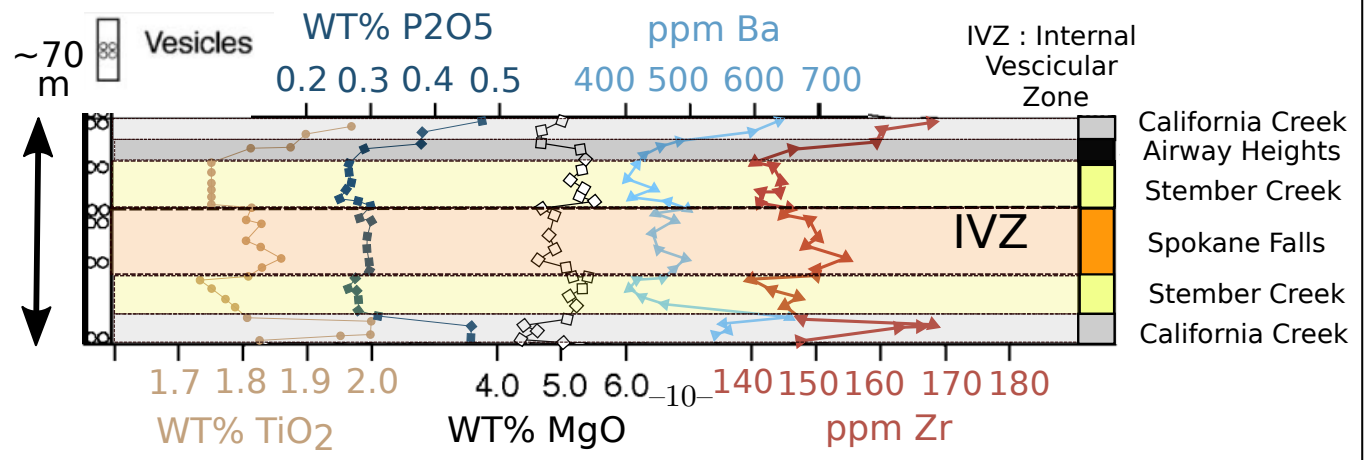

This article is protected by copyrignt. All rignts reservea.

Figure 1: Emplacement of two $10 \mathrm{~m}$-thick lava slabs where the second slab is emplaced after 3.0 years (left), 2.3 months (middle), and 17 days (right). Top: evolution of the tem- 

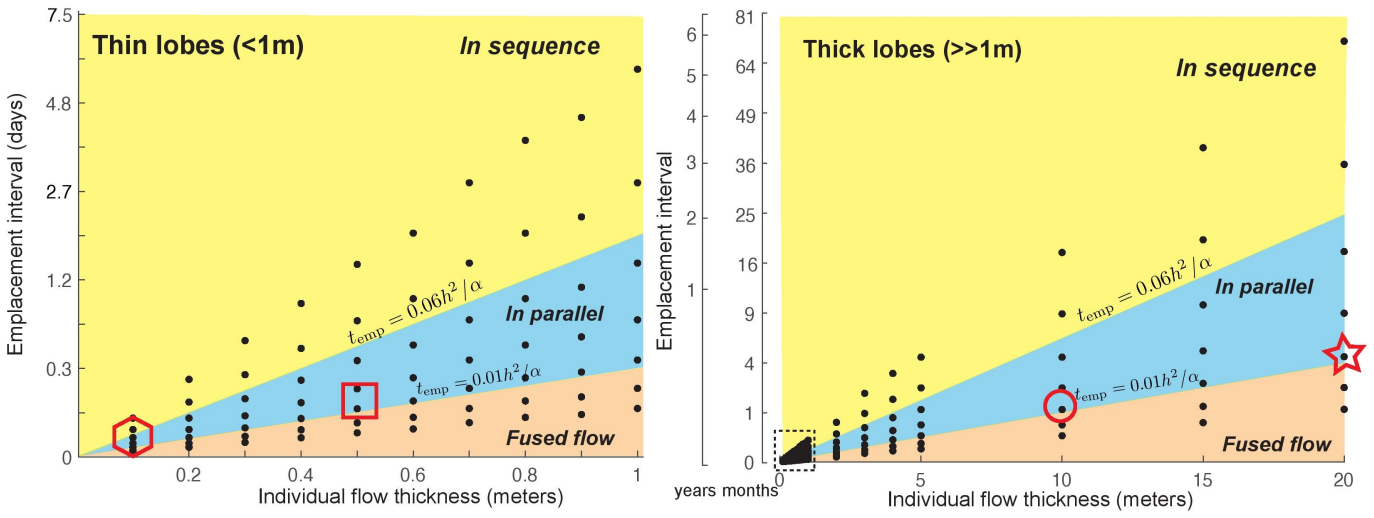

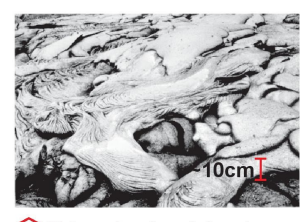

Thin pahoehoe lobes in Kupaianaha flow field, being emplaced in 1991
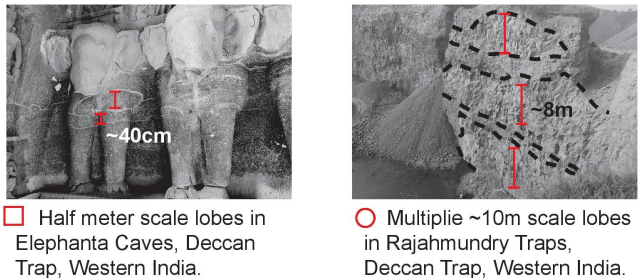

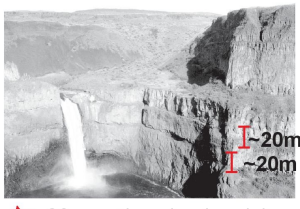

i) $20 \mathrm{~m}$ scale pahoehoe lobes in CRBG.

Figure 2: Regime diagram of two-lobe emplacement with different flow thickness and emplacement intervals, focusing on thin (left) and thick lobes (right). The black dots mark the cases we have simulated using our model. The four red outlining markers in the top two panels correspond to the observed examples in the bottom four panels, as explained in the main text. In the two scatter plots - for which the tick mark spacing scales quadratically along the vertical axis, i.e., with $t_{\mathrm{emp}}^{2}$ rather than $t_{\mathrm{emp}}$, so that the trend is roughly linear with $h$ - we omit the top two lines of points corresponding to $t_{\mathrm{emp}}=2^{3} t_{h}, 2^{4} t_{h}$ for sake of visual clarity. The example $20 \mathrm{~m}$ scale lobes in CRBG is taken at Palouse Falls, Washington, USA (Sheth, 2017). See Figures S10 and S11 for high-resolution versions of the last two examples.
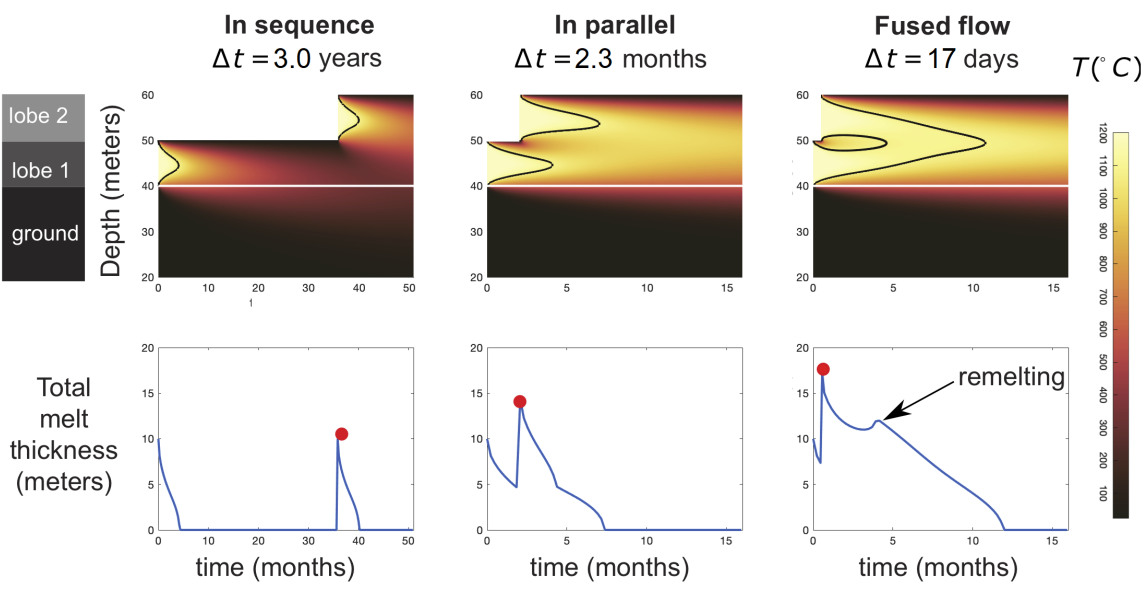

Figure 3: Stratigraphic sections for multiple Cohassett flow outcrops and cores in the Pasco Basin, Columbia River Basalts. (A) Regional Map showing the location of the sections plotted in the figure (red points) and other drill cores with similar stratigraphy (blue stars). (B) Internal stratigraphy of the Cohassett flow in the Sentinel Gap outcrop with zoomed-in pictures (B1, B2) showing the sharp... (caption continued on next page) 
Figure 3: (cont'd.)...vesicularity transitions at the Internal Vesicular Zone (IVZ) $\sim 20 \mathrm{~m}$ from the flow top (modified from McMillan et al. 1989). The location of this outcrop is shown in 3A (119 54'52”W, $\left.4647^{\prime} 50^{\prime \prime} N\right)$. Coll ${ }^{m}$ - Columnar, Ent - Entablature, and Col - Colonnade - the jointing pattern is divided into three categories: Col, Ent, and Coll ${ }^{m}$ Ent (which is intermediate between the two end-members). The right panels show the vesicle porosity and geochemical variations in the DC-16 borehole. Panels (C) and (D) show stratigraphic sections with geochemical and textural variations in the Cohassett flow in the RRl-6 Core and DC-6 cores respectively; data from Reidel (2005). We also show the assigned compositional types to parts of the Cohassett flow by Reidel (2005). 


\section{Acknowledgments}

X.F. acknowledges the support of the Miller Fellowship. S.S. would like to acknowledge the support of D. Basu, K. Das, and the Center for Nuclear Waste Regulatory Analyses for carrying out an earlier version of this study. M.M., S.S., and T.M. were supported by NSF 1615203. T.M. acknowledges funding support from the Crosby Postdoc Fellowship at MIT. All relevant simulation data, movies, figures, and codes can be found at https://zenodo.org/badge/latestdoi/357729300. In particular, all data files are contained in finaldata.zip, all codes can be found in the folder finalcodes, all relevant figures from this paper can be found in the folder finalfigures, and all movies (plus some extra movies) can be found in the folder movies.

\section{References}

Abbott, K., \& Richards, M. A. (2020). Elastic flexure of young, overlapping basaltic lava flows offshore the Galápagos and Hawaiian Islands: Observations, modeling, and thermal/chronological analysis. Geochemistry, Geophysics, Geosystems, 21 (3), e2019GC008864. doi: 10.1029/2019gc008864

Anderson, D. M., McFadden, G. B., \& Wheeler, A. A. (1998). Diffuse-interface methods in fluid mechanics. Annual Review of Fluid Mechanics, 30(1), 139165. doi: 10.1146/annurev.fluid.30.1.139

Anderson, S. W., Stofan, E., Smrekar, S., Guest, J., \& Wood, B. (1999). Pulsed inflation of phoehoe lava flows: implications for flood basalt emplacement. Earth and Planetary Science Letters, 168(1-2), 7-18. doi: 10.1016/S0012-821X(99) 00044-8

Atkinson, K. E. (1988). An introduction to numerical analysis. New York: Wiley.

Audunsson, H., \& Levi, S. (1988). Basement heating by a cooling lava: Paleomagnetic constraints. Journal of Geophysical Research, 93(B4), 3480-3496. doi: 10 .1029/JB093iB04p03480

Baloga, S. M., Glaze, L. S., Peitersen, M. N., \& Crisp, J. A. ～(2001). Influence of volatile loss on thickness and density profiles of active basaltic flow lobes. Journal of Geophysical Research: Solid Earth, 106(B7), 13395-13405. $\quad$ doi: 10.1029/2000JB900475

Baloga, S. M., Mouginis-Mark, P. J., \& Glaze, L. ～(2003). Rheology of a long lava flow at Pavonis Mons, Mars. Journal of Geophysical Research: Planets, 108(E7). doi: 10.1029/2002JE001981

Basu, D., Das, K., \& Self, S. (2012). Numerical simulations and analysis of lava flow cooling [Report to US Nuclear Regulatory Commission]. (NRC 02-07-006, IM 14002.01.441.148)

Basu, D., Das, K., \& Self, S. (2013). Numerical analysis of lava cooling with different geometric configurations [Report to US Nuclear Regulatory Commission]. (NRC 02-07-006 and HQ12C020089; IM 17860.09.001.380)

Boettinger, W. J., Warren, J. a., Beckermann, C., \& Karma, A. (2002). Phase-field simulation of solidification. Annual Review of Materials Research, 32(1), 163194. doi: 10.1146/annurev.matsci.32.101901.155803

Bryan, S. E., \& Ernst, R. E. (2008). Revised definition of large igneous provinces (LIPs). Earth-Science Reviews, 86(1-4), 175-202. doi: 10.1016/j.earscirev.2007 .08 .008

Cahn, J. W., \& Hilliard, J. E. (1958). Free Energy of a Nonuniform System. I. Interfacial Free Energy. The Journal of Chemical Physics, 28(2), 258. doi: 10.1063/ 1.1744102

Cashman, K. V., \& Kauahikaua, J. P. (1997). Reevaluation of vesicle distributions in basaltic lava flows. Geology, 25(5), 419-422. doi: 10.1130/0091-7613(1997) 025<0419:ROVDIB $\rangle$ 2.3.CO;2

Cashman, K. V., \& Marsh, B. D. (1988). Crystal size distribution (csd) in rocks and the kinetics and dynamics of crystallization II: Makaopuhi lava lake. Contribu- 
tions to Mineralogy and Petrology, 99(3), 292-305. doi: 10.1007/BF00375363

Chen, Y., Li, C., Ren, X., Liu, J., Wu, Y., Lu, Y., ... Zhang, X. (2018). The thickness and volume of young basalts within Mare Imbrium. Journal of Geophysical Research: Planets, 123(2), 630-645. doi: 10.1002/2017je005380

Chevrel, M. O., Labroquère, J., Harris, A. J., \& Rowland, S. K. (2018). PyFLOWGO: An open-source platform for simulation of channelized lava thermo-rheological properties. Computers $\&$ Geosciences, 111, 167-180. doi: 10.1016/j.cageo.2017.11.009

Clapham, M. E., \& Renne, P. R. (2019). Flood basalts and mass extinctions. Annual Review of Earth and Planetary Sciences, 47, 275-303. doi: 10.1146/annurev-earth-053018-060136

Cooper, R., \& Kohlstedt, D. (1982). Interfacial energies in the olivine basalt system. Journal of Fluid Mechanics, 217-228. doi: 10.1007/978-94-009-7867-6_17

DeGraff, J. M., Long, P. E., \& Aydin, A. (1989). Use of joint-growth directions and rock textures to infer thermal regimes during solidification of basaltic lava flows. Journal of Volcanology and Geothermal Research, 38(3-4), 309-324. doi: 10.1016/0377-0273(89)90045-0

Dole, G., Patil-Pillai, S., \& Kale, V. S. (2020). Multi-tiered, disrupted crust of a sheet lava flow from the Diveghat Formation of Deccan Traps: Implications on emplacement mechanisms. Journal of Earth System Science, 129(1), 1-9. doi: 10.1007/s12040-020-01418-9

Du, J., Wieczorek, M. A., \& Fa, W. (2020). Thickness of lava flows within the northern smooth plains on Mercury as estimated by partially buried craters. Geophysical Research Letters, 47(20), e2020GL090578. $\quad$ doi: 10.1029/2020GL090578

Du, L., Wang, L., Zheng, B., \& Du, H. (2016). Phase-field modeling of microstructure evolution during solidification in presence of gas bubble. Computational Materials Science, 114, 94-98. doi: 10.1016/j.commatsci.2015.12.018

Enns, A., \& Robinson, M. (2013). Basaltic layers exposed in lunar mare craters. In Lunar and planetary science conference (p. 2751).

Fendley, I. M., Sprain, C. J., Renne, P. R., Arenillas, I., Arz, J. A., Gilabert, V., ... Mittal, T. (2020a). No Cretaceous-Paleogene boundary in exposed Rajahmundry Traps: A refined chronology of the longest Deccan lava flows from 40Ar/39Ar dates, magnetostratigraphy, and biostratigraphy. Geochemistry, Geophysics, Geosystems, 21 (9), 1-20. doi: 10.1029/2020GC009149

Fendley, I. M., Sprain, C. J., Renne, P. R., Arenillas, I., Arz, J. A., Gilabert, V., ... others (2020b). No Cretaceous-Paleogene Boundary in exposed Rajahmundry Traps: A refined chronology of the longest Deccan lava flows from 40ar/39ar dates, magnetostratigraphy, and biostratigraphy. Geochemistry, Geophysics, Geosystems, 21(9), e2020GC009149. doi: 10.1029/2020GC009149

Forbes, A. E., Blake, S., \& Tuffen, H. (2014). Entablature: fracture types and mechanisms. Bulletin of Volcanology, 76 (5), 1-13. doi: 10.1007/s00445-014-0820-z

Fujii, M. (1991). An extension of Milne's device for the Adams Predictor-Corrector Methods. Japan Journal of Industrial and Applied Mathematics, 8(1), 1-18. doi: $10.1007 / \mathrm{BF} 03167183$

Garcia, M. O., Pietruszka, A. J., Norman, M. D., \& Rhodes, J. M.

(2021). K̄̄lauea's pu u ō ō eruption (1983-2018): A synthesis of magmatic processes during a prolonged basaltic event. Chemical Geology, 120391 doi: 10.1016/j.chemgeo.2021.120391

Gifford, A. W., \& El-Baz, F. (1981). Thicknesses of lunar mare flow fronts. The moon and the planets, 24(4), 391-398. doi: 10.1007/BF00896904

Giuliani, L., Iezzi, G., Vetere, F., Behrens, H., Mollo, S., Cauti, F., .. S Scarlato, P. (2020). Evolution of textures, crystal size distributions and growth rates of plagioclase, clinopyroxene and spinel crystallized at variable cooling rates from a mid-ocean ridge basaltic melt. $\quad$ Earth-Science Reviews, 204, 103165. doi: 
10.1016/j.earscirev.2020.103165

Glaze, L. S., Baloga, S. M., \& Stofan, E. R. (2003). A methodology for constraining lava flow rheologies with MOLA. Icarus, 165(1), 26-33. doi: 10.1016/S0019 $-1035(03) 00171-4$

Guest, J. E., Bulmer, M. H., Aubele, J., Beratan, K., Greeley, R., Head, J. W., ... Wiles, C. (1992). Small volcanic edifices and volcanism in the plains of Venus. Journal of Geophysical Research: Planets, 97(E10), 15949-15966. doi: 10.1029/92JE01438

Hamilton, C. W., Scheidt, S. P., Sori, M. M., de Wet, A. P., Bleacher, J. E., Mouginis-Mark, P. J., ... others (2020). Lava-rise plateaus and inflation pits in the McCartys lava flow field, New Mexico: An analog for pāhoehoe-like lava flows on planetary surfaces. Journal of Geophysical Research: Planets, 125(7), e2019JE005975. doi: 10.1029/2019JE005975

Harris, A. J., \& Rowland, S. (2001). FLOWGO: A kinematic thermo-rheological model for lava flowing in a channel. Bulletin of Volcanology, 63(1), 20-44. doi: $10.1007 / \mathrm{s} 004450000120$

Hartlieb, P., Toifl, M., Kuchar, F., Meisels, R., \& Antretter, T. (2016). Thermophysical properties of selected hard rocks and their relation to microwaveassisted comminution. Minerals Engineering, 91, 34-41. doi: 10.1016/ j.mineng.2015.11.008

Hiesinger, H., Head, J., Wolf, U., Jaumann, R., \& Neukum, G. (2011). Ages and stratigraphy of lunar mare basalts: A synthesis. Recent advances and current research issues in lunar stratigraphy, 477, 1-51. doi: 10.1130/2011.2477(01)

Hiesinger, H., Head Iii, J., \& Neukum, G. (2007). Young lava flows on the eastern flank of Ascraeus Mons: Rheological properties derived from High Resolution Stereo Camera (HRSC) images and Mars Orbiter Laser Altimeter (MOLA) data. Journal of Geophysical Research: Planets, 112(E5). doi: 10.1029/2006JE002717

Hiesinger, H., Head III, J., Wolf, U., Jaumann, R., \& Neukum, G. Lunar mare basalt flow units: Thicknesses determined from crater sizefrequency distributions. $\quad$ Geophysical Research Letters, 29(8), 89-1. Ioi: 10.1029/2002GL014847

Hoblitt, R. P., Orr, T. R., Heliker, C., Denlinger, R. P., Hon, K., \& Cervelli, P. F. (2012). Inflation rates, rifts, and bands in a phoehoe sheet flow. Geosphere, 8(1), 179-195. doi: 10.1130/GES00656.1

Hon, K., Kauahikaua, J., Denlinger, R., \& Mackay, K. (1994). Emplacement and inflation of phoehoe sheet flows: observations and measurements of active lava flows on Klauea Volcano, Hawaii. Geological Society of America Bulletin, 106 (3), 351-370. doi: 10.1130/0016-7606(1994)106〈0351:EAIOPS $\rangle 2.3 . C O ; 2$

Jaupart, C., \& Mareschal, J. (2010). Heat generation and transport in the earth. Cambridge University Press. doi: 10.1017/CBO9780511781773

Kale, V. S., Dole, G., Shandilya, P., \& Pande, K. (2020). Stratigraphy and correlations in Deccan Volcanic Province, India: Quo vadis? GSA Bulletin, 132(3-4), 588-607. doi: 10.1130/B35018.1

Kauahikaua, J., Cashman, K. V., Mattox, T. N., Heliker, C. C., Hon, K. A., Mangan, M. T., \& Thornber, C. R. (1998). Observations on basaltic lava streams in tubes from Klauea Volcano, island of Hawai'i. Journal of Geophysical Research: Solid Earth, 103(B11), 27303-27323. doi: 10.1029/97JB03576

Keszthelyi, L. (1994). Calculated effect of vesicles on the thermal properties of cooling basaltic lava flows. Journal of Volcanology and Geothermal Research, 63(34), 257-266. doi: 10.1016/0377-0273(94)90078-7

Kim, S. G., \& Kim, W. T. (2005). Phase-Field Modeling of Solidification. In Handbook of materials modeling (pp. 2105-2116). Springer, Dordrecht. doi: 10.1007/ 978-1-4020-3286-8_109

Lancaster, M. G., Guest, J. E., \& Magee, K. P. (1995). Great lava flow fields on 
Venus. Icarus, 118(1), 69-86. doi: 10.1006/icar.1995.1178

Long, P. E., \& Wood, B. J. (1986). Structures, textures, and cooling histories of columbia river basalt flows. Geological Society of America Bulletin, 97(9), 1144-1155. doi: 10.1130/0016-7606(1986)97/1144:STACHO $\rangle 2.0 . C O ; 2$

Lundgren, P., Bagnardi, M., \& Dietterich, H. (2019). Topographic changes during the 2018 Klauea eruption from single-pass airborne InSAR. Geophysical Research Letters, 46 (16), 9554-9562. doi: 10.1029/2019GL083501

MacLellan, L., Ernst, R., El Bilali, H., Ghail, R., \& Bethell, E. (2021). Volcanic history of the Derceto large igneous province, Astkhik Planum, Venus. EarthScience Reviews, 103619. doi: 10.1016/j.earscirev.2021.103619

McMillan, K., Long, P. E., \& Cross, R. W. (1989). Vesiculation in Columbia River basalts. Geological Society of America Special Papers, 239, 157-168. doi: 10 $.1130 /$ SPE239-p157

Moore, H., Plaut, J., Schenk, P., \& Head, J. (1991). Thick lava flows on Venus. In Bulletin of the american astronomical society (Vol. 23, p. 1222).

Moore, H., Plaut, J., Schenk, P., \& Head, J. (1992). An unusual volcano on Venus. Journal of Geophysical Research: Planets, 97(E8), 13479-13493. doi: 10.1029/ 92JE00957

Morota, T., Haruyama, J., Ohtake, M., Matsunaga, T., Honda, C., Yokota, Y., ... others (2011). Timing and characteristics of the latest mare eruption on the Moon. Earth and Planetary Science Letters, 302(3-4), 255-266. doi: 10.1016/J.EPSL.2010.12.028

Mouginis-Mark, P. J., \& Rowland, S. K. (2008). Lava flows at Arsia Mons, Mars: Insights from a graben imaged by HiRISE. Icarus, 198(1), 27-36. doi: 10 $.1016 /$ j.icarus.2008.06.015

Mouginis-Mark, P. J., \& Yoshioka, M. T. (1998). The long lava flows of Elysium Planita, Mars. Journal of Geophysical Research: Planets, 103(E8), 1938919400. doi: 10.1029/98JE01126

Patel, V., Sheth, H., Cucciniello, C., Joshi, G. W., Wegner, W., Samant, H., ... Koeberl, C. (2020). Geochemistry of Deccan tholeiite flows and dykes of Elephanta Island: Insights into the stratigraphy and structure of the Panvel flexure zone, western Indian rifted margin. Geosciences, 10(4). Retrieved from https://www.mdpi.com/2076-3263/10/4/118 doi: 10.3390/geosciences10040118

Patrick, M. R., Dehn, J., \& Dean, K. (2004). Numerical modeling of lava flow cooling applied to the 1997 Okmok eruption: Approach and analysis. Journal of Geophysical Research, 109(B3), B03202. doi: 10.1029/2003JB002537

Peck, D. L., Hamilton, M. S., \& Shaw, H. R. (1977). Numerical analysis of lava lake cooling models; Part II, application to Alae lava lake, Hawaii. American Journal of Science, 277(4), 415-437. doi: 10.2475/ajs.277.4.415

Peters, S. (2020). Investigating lava flow emplacement: Implications for volcanic hazards and planetary evolution. ProQuest Dissertations and Theses, 238. Retrieved from https://clsproxy.library.caltech.edu/dissertations -theses/investigating-lava-flow-emplacement-implications/docview/ $2441550711 /$ se-2?accountid $=9841$

Phillips, J. C., Humphreys, M. C., Daniels, K., Brown, R., \& Witham, F. (2013). The formation of columnar joints produced by cooling in basalt at Staffa, Scotland. Bulletin of Volcanology, 75 (6), 1-17. doi: 10.1007/s00445-013-0715-4

Philpotts, A. R., \& Philpotts, D. E. (2005). Crystal-mush compaction in the Cohassett flood-basalt flow, Hanford, Washington. Journal of Volcanology and Geothermal Research, 145(3-4), 192-206. doi: 10.1016/ j.jvolgeores.2005.01.008

Provatas, N., \& Elder, K. (2010). Phase-field methods in materials science and engineering (1st ed.). Wiley. doi: 10.1002/9783527631520

Puffer, J. H., Block, K. A., Steiner, J. C., \& Laskowich, C. (2018). Complex layer- 
ing of the Orange Mountain Basalt: New Jersey, USA. Bulletin of Volcanology, 80 (6), 54. doi: 10.1007/s00445-018-1231-3

Qian, Y., Xiao, L., Head, J. W., van der Bogert, C. H., Hiesinger, H., \& Wilson, L. (2021). Young lunar mare basalts in the Chang'e-5 sample return region, northern Oceanus Procellarum. Earth and Planetary Science Letters, 555, 116702. doi: $10.1016 /$ j.epsl.2020.116702

Qian, Y., Xiao, L., Wang, Q., Head, J. W., Yang, R., Kang, Y., ... others China's Chang'e-5 landing site: Geology, stratigraphy, and provenance of materials. Earth and Planetary Science Letters, 561, 116855. 10.1016/j.epsl.2021.116855

Rader, E., Vanderkluysen, L., \& Clarke, A. (2017). The role of unsteady effusion rates on inflation in long-lived lava flow fields. Earth and Planetary Science Letters, 477, 73-83. doi: 10.1016/j.epsl.2017.08.016

Ralston, A. (1962). Runge-Kutta methods with minimum error bounds. Mathematics of Computation, 16(80), 431-437. doi: 10.1090/S0025-5718-1962-0150954 $-0$

Reidel, S. P. (2005). A lava flow without a source: The Cohassett flow and its compositional components, Sentinel Bluffs Member, Columbia River Basalt Group. The Journal of geology, 113(1), 1-21. doi: 10.1086/425966

Reidel, S. P. (2006). Comment on Philpotts and Philpotts (2005): Crystalmush compaction in the Cohassett flood-basalt flow, Hanford, Washington. Journal of Volcanology and Geothermal Research, 152(1), 189-193. doi: 10.1016/j.jvolgeores.2005.11.001

Rumpf, M. E., Needham, H., \& Fagents, S. A. (2020). Thicknesses of lava flows in satellite images: Comparison of layered mare units with terrestrial analogs. Icarus, 350, 113853. doi: 10.1016/j.icarus.2020.113853

Self, S., Jay, A. E., Widdowson, M., \& Keszthelyi, L. P. (2008). Correlation of the Deccan and Rajahmundry Trap lavas: Are these the longest and largest lava flows on Earth? Journal of Volcanology and Geothermal Research, 172(1-2), 3-19. doi: 10.1016/j.jvolgeores.2006.11.012

Self, S., Keszthelyi, L., \& Thordarson, T. (1998). The importance of pāhoehoe. Annual Review of Earth and Planetary Sciences, 26(1), 81-110. doi: 10.1146/ annurev.earth.26.1.81

Self, S., Mittal, T., \& Jay, A. E. $\quad$ (2021). Thickness characteristics of pāhoehoe lavas in the Deccan Province, Western Ghats, India, and in continental flood basalt provinces elsewhere. Frontiers in Earth Science, 8, 720. doi: $10.3389 /$ feart.2020.630604

Self, S., Schmidt, A., \& Mather, T. (2014). Emplacement characteristics, time scales, and volcanic gas release rates of continental flood basalt eruptions on Earth. In Volcanism, Impacts, and Mass Extinctions: Causes and Effects. Geological Society of America. doi: 10.1130/2014.2505(16)

Self, S., Thordarson, T., Keszthelyi, L., Walker, G., Hon, K., Murphy, M., ... Finnemore, S. (1996). A new model for the emplacement of Columbia River basalts as large, inflated phoehoe lava flow fields. Geophysical Research Letters, 23(19), 2689-2692. doi: 10.1029/96GL02450

Sheth, H. (2017). Morphology and architecture of flood basalt lava flows and sequences. $\quad$ In A photographic atlas of flood basalt volcanism (pp. 33-79). Springer International Publishing. doi: 10.1007/978-3-319-67705-7_3

Snyder, D. (2002). Cooling of lava flows on Venus: The coupling of radiative and convective heat transfer. Journal of Geophysical Research, 107(E10). doi: 10 $.1029 / 2001 \mathrm{je} 001501$

Spry, A. (1962). The origin of columnar jointing, particularly in basalt flows. Journal of the Geological Society of Australia, 8(2), 191-216. doi: 10.1080/ 14400956208527873

Spudis, P. D., \& Guest, J. E. (1988). Stratigraphy and geologic history of Mer- 
cury. In F. Vilas, C. R. Chapman, \& M. S. Matthews (Eds.), Mercury (pp. 118-164). University of Arizona Press.

Thordarson, T., \& Self, S. (1998). The Roza Member, Columbia River Basalt Group: A gigantic phoehoe lava flow field formed by endogenous processes? Journal of Geophysical Research: Solid Earth, 103(B11), 27411-27445. Ioi: 10.1029/98JB01355

Tomkeieff, S. I. (1940). The basalt lavas of the Giants Causeway district of Northern Ireland. Bulletin of Volcanology, 6(1), 89-143. doi: 10.1007/BF02994875

Touloukian, Y., Powell, R., Ho, C., \& Klemens, P. (1971). Thermophysical properties of matter - The TPRC data series. Volume 2. Thermal conductivity Nonmetallic solids. Defense Technical Information Center.

USGS. (2019). Klauea 2018 lower East Rift Zone lava flow thicknesses: A preliminary map. USGS (U.S. Geological Survey). Retrieved from https ://www .usgs.gov/maps/k-lauea-2018-lower-east-rift-zone-lava -flow-thicknesses-a-preliminary-map

Vye-Brown, C., Self, S., \& Barry, T. (2013). Architecture and emplacement of flood basalt flow fields: case studies from the Columbia River Basalt Group, NW USA. Bulletin of Volcanology, 75(3), 697. doi: 10.1007/s00445-013-0697-2

Whittington, A. G., \& Sehlke, A. (2021). Spontaneous reheating of crystallizing lava. Geology. doi: 10.1130/G49148.1

Wilson, L., \& Head, J. W. (2008). Volcanism on Mercury: A new model for the history of magma ascent and eruption. Geophysical Research Letters, 35(23). doi: 10.1029/2008GL035620

Worster, M. G., Huppert, H. E., \& Sparks, R. S. J. (1993). The crystallization of lava lakes. Journal of Geophysical Research, 98(B9), 15891. doi: 10.1029/ 93JB01428

Wright, T. L., \& Marsh, B. (2016). Quantification of the intrusion process at Klauea Volcano, Hawaii. Journal of Volcanology and Geothermal Research, 328, 34-44. doi: 10.1016/j.jvolgeores.2016.09.019

Wright, T. L., \& Okamura, R. T. (1977). Cooling and crystallization of tholeiitic basalt, 1965 Makaopuhi Lava Lake, Hawaii (Tech. Rep.). doi: $10.3133 / \mathrm{pp} 1004$

Wright, T. L., Peck, D. L., \& Shaw, H. R. (1976). Klauea lava lakes: Natural laboratories for study of cooling, crystallization, and differentiation of basaltic magma. In The geophysics of the pacific ocean basin and its margin (p. 375390). American Geophysical Union (AGU). doi: 10.1029/GM019p0375

Wroblewski, F. B., Treiman, A. H., Bhiravarasu, S., \& Gregg, T. K. Ovda Fluctus, the festoon lava flow on Ovda Regio, Venus: Not silicarich. Journal of Geophysical Research: Planets, 124(8), 2233-2245. doi: 10.1029/2019JE006039

Yuan, Y., Wang, F., Zhu, P., Xiao, L., \& Zhao, N. (2020). New constraints on the young lava flow profile in the northern Mare Imbrium. Geophysical Research Letters, 47(16), e2020GL088938. doi: 10.1029/2020GL088938

Zimbelman, J. R. (1998). Emplacement of long lava flows on planetary surfaces. Journal of Geophysical Research: Solid Earth, 103(B11), 27503-27516. doi: 10 .1029/98JB01123

Zimbelman, J. R. (2003). Flow field stratigraphy surrounding Sekmet Mons Volcano, Kawelu Planitia, Venus. Journal of Geophysical Research: Planets, 108(E5). doi: 10.1029/2002JE001965

Zlatev, Z. (1985). Variable stepsize variable formula methods based on predictorcorrector schemes. Applied Numerical Mathematics, 1(5), 395-416. doi: 10 .1016/0168-9274(85)90003-0 